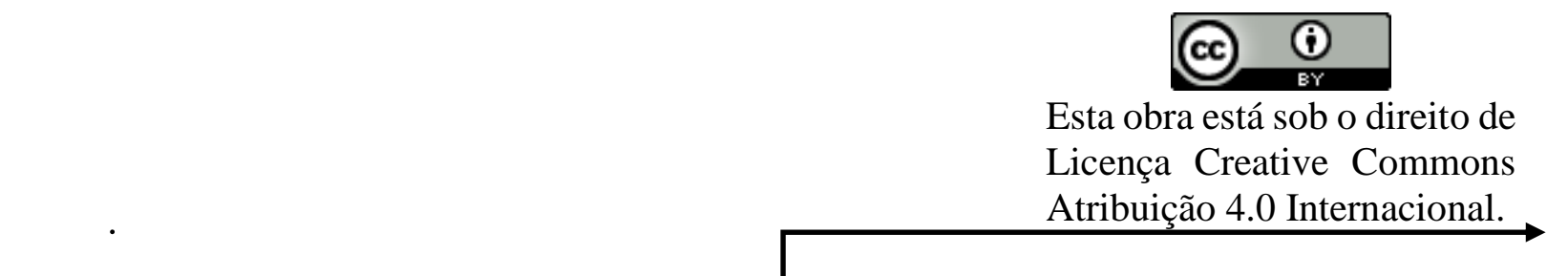

\title{
FATORES QUE INTERFEREM NO VALOR NUTRICIONAL DOS NUTRIENTES
} DE ALIMENTOS

\author{
Rosa Cavalcante Lira ${ }^{l}$ \\ Thales José de Lima Belém ${ }^{2}$ \\ Alany Cristyane Felix da Silva ${ }^{3}$ \\ Aliny Cristyna Felix da Silva ${ }^{4}$ \\ Paulo Vanderlei Ferreira ${ }^{5}$ \\ Elton Lima Santos ${ }^{6}$ \\ Sofia Pessoa Lira Souza ${ }^{7}$ \\ José Edmar de Lira ${ }^{8}$
}

\section{RESUMO}

O valor nutritivo está diretamente relacionado com a sua composição química, a disponibilidade dos nutrientes e a concentração energética do alimento que atendam corretamente às exigências das espécies animais no balanceamento de rações. Diversos fatores interferem na ingestão e utilização de nutrientes pelos animais, como a composição química e valores energéticos, a digestibilidade, a absorção e o metabolismo. Esta revisão tem por objetivo identificar os fatores que interferem no valor nutricional dos nutrientes de alimentos. Trata-se de uma revisão de literatura tradicional, não sistemática, de caráter exploratório e qualitativo. Fez-se necessária leitura, análise e interpretação de livros, periódicos, anais de eventos científicos e teses de doutorado, obtidos em bibliotecas físicas e virtuais, publicados no período de 1975 a 2016 . A partir da análise dos documentos surgiram as seguintes categorias temáticas: digestibilidade, teor de fibra dos alimentos, fatores antinutricionais, efeito idade do animal e efeito do nível de inclusão e de substituição.

Palavras-chave: digestibilidade; nutrientes; fatores antinutricionais; idade do animal; nível de inclusão.

\footnotetext{
${ }^{1}$ Possui graduação em Medicina Veterinária pela Universidade Federal Rural de Pernambuco (1984), mestrado em Zootecnia pela Universidade Federal Rural de Pernambuco (1990) e doutorado em Programa de Doutorado Integrado em Zootecnia pela Universidade Federal Rural de Pernambuco (2008).

${ }^{2}$ Possui graduação em zootecnia pela Universidade Federal de Alagoas (2018).

${ }^{3}$ Possui graduação em Zootecnia pela Universidade Federal de Alagoas (2019). Mestranda em Produção Animal pela Universidade Federal de Sergipe.

${ }^{4}$ Graduanda em Zootecnia pela Universidade Federal de Alagoas.

${ }^{5}$ Possui graduação em agronomia pela Universidade Federal de Alagoas (1974), mestrado em agronomia (Genética e Melhoramento de Plantas) pela Universidade de São Paulo, doutorado em agronomia (Genética e Melhoramento de Plantas) pela Universidade de São Paulo.

6 Possui graduação em Zootecnia pela Universidade Federal de Alagoas (2005), mestrado e doutorado em Zootecnia (Nutrição Animal) pela Universidade Federal Rural de Pernambuco (2007).

${ }^{7}$ Possui graduação em Arquitetura e Urbanismo pelo Centro Universitário CESMAC (2011), mestre em Dinâmica do Espaço Habilitado pela Universidade Federal de Alagoas (2015), doutoranda do Espaço Habilitado Pela Universidade Federal de Alagoas.

${ }^{8}$ Possui Graduação em Medicina Veterinária pela Universidade Federal Rural de Pernambuco (1985), Mestrado em Zootecnia pela Universidade Federal Rural de Pernambuco (1992), Doutorado em Zootecnia (2004) pela Universidade Federal da Paraíba e Pós-Doutorado (2015) pela Universidade Federal da Paraíba. Atualmente é professor Associado IV da Universidade Federal de Alagoas.
} 


\section{INTRODUÇÃO}

A influência da nutrição na produção animal é evidente, uma vez que na elaboração de planos nutricionais que propiciem excelentes desempenho dos animais, deve-se, no processo de formulação das suas rações, combinar as exigências nutricionais dos animais com os valores nutricionais dos alimentos utilizados na sua elaboração (MELLO et al.,2009).

Desta forma, o uso de alimentos convencionais ou alternativos na dieta dos animais exige o conhecimento das suas qualidades nutritivas, no sentido de que se possa fornecer aos animais os nutrientes por eles requeridos e que não tenham influência negativa no desempenho produtivo dos mesmos, já que dietas balanceadas de forma inadequada aumentam o consumo de ração, reduzem o ganho de peso e pioram a conversão alimentar, determinando aumento dos custos de produção (BRUM et al., 1999).

O valor nutritivo está diretamente relacionado com a sua composição química,

\section{METODOLOGIA}

Trata-se de uma revisão de literatura tradicional, não sistemática, de caráter exploratório e qualitativo. Fez-se necessária a disponibilidade dos nutrientes e a concentração energética do alimento que atendam corretamente às exigências das espécies animais no balanceamento de rações, mas não deve ser considerado um fator isolado, mas como um complexo formado por fatores que interferem na sua ingestão e utilização pelos animais, como a composição química e valores energéticos, a digestibilidade, a absorção e o metabolismo (ABRAHÃO, 1991).

Dessa forma a simples quantificação dos nutrientes nos ingredientes utilizados nas rações fornece apenas informações sobre o conteúdo total desses nutrientes no alimento, mas desconsideram que uma fração desses nutrientes nos alimentos não é absorvida e disponibilizada, ou simplesmente é excretada, por isso é importante, na caracterização de um nutriente para sua utilização na alimentação animal, que ele seja avaliado química, física e biologicamente e que, em seguida, considere-se os resultados (LIMA et al., 1989).

leitura, análise e interpretação de livros, periódicos, anais de eventos científicos e teses de doutorado, obtidos em bibliotecas físicas e virtuais, publicados no período de 1975 a 2016. 


\section{RESULTADOS E DISCUSSÃO}

A partir da análise dos documentos surgiram as seguintes categorias temáticas: digestibilidade, teor de fibra dos alimentos, fatores antinutricionais, efeito idade do animal e efeito do nível de inclusão e de substituição.

\section{Digestibilidade}

Com relação a digestibilidade, sabemos que alguns alimentos apresentam maior ou menor digestibilidade de seus nutrientes, com variação considerável na digestibilidade entre diferentes amostras do mesmo alimento, indicando que a digestibilidade, não é uma característica somente ligada ao alimento, mas que sofre influência da interação animal/alimento e de vários fatores, dos quais se destacam a espécie, a raça, a linhagem, a idade, o peso, o consumo da ração e água, o estado clínico dos animais, a atividade microbiana do lúmen intestinal, a ação das enzimas endógenas do animal, a influência da temperatura ambiente e a taxa de passagem do alimento pelo trato digestivo, , as condições, a qualidade, o tipo e o grau de processamento do alimento; a interação com outros nutrientes; os níveis de inclusão dos alimentos; os fatores nutricionais na ração; o nível de consumo do alimento e ainda e os métodos de avaliação de digestibilidade (ALBINO, 1991;

PANIGRAHI; 1992; TORRES, 2003).

Com relação à interferência da ação das enzimas endógenas do animal sobre a digestibilidade, Macari et al. (1994) afirmam que a digestibilidade das proteínas é influenciada pela sua estrutura química, sendo mais difícil em proteínas com estrutura tridimensional, e pela sua origem, com as proteínas de origem animal sendo consideradas mais digestíveis e ainda que a presença e o tipo de carboidrato na dieta influenciam, também, na digestibilidade das proteínas.

Misir e Sauer (1982) citam que a fonte de carboidratos da dieta influencia a digestibilidade aparente do alimento, observando que o amido, quando é altamente digestível, pode superestimar a digestibilidade aparente, ocorrendo o contrário, quando é menos digestível.

\section{Teor de fibra dos alimentos}

Em decorrência da demanda de alimentos de alta energia para uso na alimentação humana houve um aumento da disponibilidade de ingredientes ricos em fibra que tem promovido um aumento da utilização desses ingredientes na alimentação de animal (NOBLET; LE GOOF, 2001). No entanto, ao se utilizar alimentos fibrosos, principalmente na alimentação de monogástricos, deve-se 
considerar que os efeitos nutricionais e fisiológicos da fibra dependem não só da quantidade de parede celular incorporada à dieta, mas também de sua composição química, estrutural e da forma como está fisicamente associada a outros nutrientes (MEDEIROS et al., 1988).

Parson et al. (1985), relatam que o teor de fibra do alimento pode reduzir a disponibilidade de nutrientes e aumentar as perdas endógenas, uma vez que provoca um aumento na produção de muco, por causar lesões nas células da mucosa intestinal que forma uma camada gelatinosa em volta do nutriente, se envolvendo com ele, diminuindo a atuação das enzimas digestivas.

A fibra é uma fração com baixo teor energético que pode interferir no tempo de trânsito intestinal do alimento e reduzir a digestibilidade de quase todos os nutrientes, inclusive da energia, devido ao aumento da excreção de nutrientes nas fezes. No entanto, a fibra aumenta o crescimento microbiano e influencia beneficamente no bem-estar e favorecem os movimentos peristálticos do intestino (WENK, 2001), além de que a inclusão de fibra na dieta leva a uma maior energia disponível para os microorganismos no intestino grosso, que se proliferam e se utilizam dos nutrientes do alimento, superestimando seus valores de digestibilidade (MISIR \& SAUER, 1982).

\section{Fatores antinutricionais}

Cousins (1999) afirma a indisponibilidade de nutriente pode ser influenciada pela formação de complexos naturais tidos como antinutricionais, que normalmente não são tóxicos para os animais, porém sua presença resulta em baixo desempenho, alterações hormonais e esporádicas lesões nos órgãos dos animais; e que o modo de ação e as propriedades físico - químicas da maioria dos fatores antinutricionais são conhecidos, o que permite a adoção de atitudes para reduzir a quantidade desses fatores na dieta, contribuindo para um melhor desempenho dos animais.

Torres (2003) relata que os fatores antinutricionais provocam a formação de gel, tornando o trânsito do alimento mais lento, diminuindo o consumo da ração e permitindo a multiplicação exagerada de bactérias intestinais produzindo ácidos que degradam enzimas responsáveis pela digestão dos lipídeos, levando à diminuição de absorção de nutrientes como pigmentos e vitaminas lipossolúveis; além da utilização de outros nutrientes, pela microflora, como o amido e as proteínas da dieta, competindo deste modo com o animal. 


\section{Efeito idade do animal}

Dentre os diversos fatores, a idade é um fator de grande influência no processo de digestão, por estar relacionada à maturação dos órgãos do sistema digestivo, incluindo a produção de enzimas digestivas e o trânsito intestinal, particularmente a taxa de passagem do alimento (NITSAN et al., 1991).

Segundo Soares (2005) por muitos anos, os produtores de frango de corte usaram programas nutricionais que incluem uma mesma dieta da eclosão até as três semanas de idade, tendo os valores nutricionais dos alimentos utilizados para esta fase sido determinados com galos adultos ou frangos de corte na fase de crescimento e destacou que na criação de frangos de corte, durante a fase pré-inicial há intenso desenvolvimento do sistema digestório, o que torna elevada a demanda por nutrientes de alta qualidade, mesmo as aves, nesta fase, possuindo reservas nutricionais advindas do saco vitelino, não são capazes de suprir suas exigências nutricionais, devido ainda não possuírem o trato gastrointestinal totalmente desenvolvido.

A idade é um fator que influencia no processo de digestão, estando relacionada à maturação dos órgãos que compõem o sistema digestivo, incluindo a produção de enzimas digestivas das aves e ainda o trânsito intestinal, particularmente a taxa de passagem do alimento (NITSAN et al.,1991).

Na eclosão, o sistema digestivo está anatomicamente completo, porém, quando comparada ao de aves adultas sua capacidade funcional é considerada imatura. No entanto, após a eclosão, os órgãos do aparelho digestório, principalmente o pâncreas, fígado e o intestino delgado, são os que mais rapidamente se desenvolvem após a eclosão, atingindo seu valor máximo de crescimento aos sete dias pós-eclosão, com o intestino sofrendo grandes alterações morfológicas e fisiológicas durante a sua maturação funcional, com aumento da área de superfície de digestão e absorção, bem como na quantidade e qualidade das secreções digestivas (MAIORKA, 2000).

Para Freitas (2003), os lipídios têm sido os nutrientes que mais sofrem influência, em relação à sua digestão e absorção, em função da idade. Whitehead e Fischer (1982), Katangole e March (1980), observaram que a energia metabolizável e a absorção das gorduras aumentaram com a idade das aves, demonstrando a influência da idade no processo de digestão e absorção de gorduras.

O efeito da idade da ave sobre o valor nutricional dos alimentos tem sido relatado em vários trabalhos onde se constatou que 
os valores das tabelas de composição de alimentos editadas no Brasil e no exterior, normalmente determinados com frangos de 16 a 25 dias ou com galos adultos e utilizados para formular rações de aves em todas as idades, não são apropriados para uso em dietas de pintinhos e estão bem acima dos realmente utilizados por eles na primeira semana. Estas pesquisas levaram a edições de tabelas brasileiras por Rostagno et al., (2000 e 2005) e pelo NRC (1994) com níveis nutricionais recomendados para frangos de corte nas fases pré-inicial e inicial (LIRA, 2008).

Assim, Menten et al. (2003) observaram que a energia metabolizável aparente do milho (3.213kcal $/ \mathrm{kg}$ de $\mathrm{Mn})$ e do farelo de soja $(2.085 \mathrm{kcal} / \mathrm{kg}$ de $\mathrm{MN})$ determinadas com pintinhos na primeira semana era inferior à encontrada na literatura para esses alimentos.

Batal; Parsons (2003) também demonstraram que a idade das aves não somente interfere nos valores de energia metabolizável, mas também na digestibilidade aparente de vários nutrientes da dieta e observaram que o valor de energia metabolizável aumenta até o $14^{\circ}$ dia e a digestibilidade da lisina até o $10^{\circ}$ dia, a partir dos quais se mantém constante.

Sakomura et al. (2004) também realizaram estudos de metabolismo, utilizando a metodologia de coleta total de excretas, objetivando verificar o efeito da idade da ave sobre a digestibilidade da energia, do extrato etéreo e da matéria seca de sojas extrusada e tostada e do farelo de soja e ainda quantificar a atividade das enzimas digestivas pancreáticas em frangos de corte de uma, duas, três, quatro e seis semanas de idade e observaram que a atividade das enzimas amilase e tripsina pancreática aumentou linearmente com a idade das aves, assim como o crescimento alométrico do pâncreas; a atividade da lípase aumentou linearmente com a idade nas aves alimentadas com a soja integral tostada, enquanto o efeito foi quadrático nas aves alimentadas com soja integral extrusada e farelo de soja; os coeficientes de digestibilidade da MS e de EE e os valores de energia metabolizáel dos tipos de soja variaram em função da idade, concluindo que o aproveitamento da energia desses alimentos varia com a idade das aves em função da sua dependência da atividade enzimática.

Objetivando determinar os valores de energia metabolizável da farinha de vísceras e da farinha de penas de aves alimentadas em duas idades (16 a 23 dias e 30 a 38 dias), Nascimento et al. (2005) realizou ensaio de metabolismo, pelo método de coleta total de excretas e observaram que o valor de EMA da farinha de vísceras e da farinha de penas não diferiu 
entre as duas idades avaliadas, porém houve efeito da idade nos valores de EMAn da farinha de vísceras, mas não havendo nos valores da farinha de penas.

Neste mesmo sentido, Brumano et al. (2006) realizaram ensaios de metabolismo em pintos de corte de 21 a 30 e de 41 a 50 dias, pelo método de coleta total de excretas, visando determinar os valores de energia metabolizável de alguns ingredientes protéicos como: farelo de algodão (FA), glúten de milho (GM), concentrado protéico de soja (CPS), farinha de carne e osso 36\% (FCO), farinha de carne e osso $45 \%$ (FCO), farinha de peixe (FP), farinha de vísceras de aves de alto teor de gordura (FVA), plasma sanguíneo $70 \%$ (PS), plasma sanguíneo 78\% (PS) e hemácias $(\mathrm{H})$ nestes períodos, observaram que os valores de EMA e EMAn dos alimentos estudados no período de 41 a 50 dias de idade foram em média 12,95\% superiores aos obtidos no período de 21 a 30 dias, indicando o efeito da idade na digestibilidade dos nutrientes e que, com o avançar da idade, as aves aproveitam melhor o alimento.

Lira et al. (2011) avaliaram o efeito da idade de frangos de corte sobre os valores nutricionais do resíduo do tomate, nas idade de 1 a 8 dias e de 10 a 17 e observaram que a idade das aves influenciou nos valores de energia metabolizável aparente e nos coeficientes de metabolizabilidade da energia do resíduo do tomate e não influenciou nos valores de energia metabolizada aparente do resíduo, indicando que não ocorreram alterações significativas na retenção de nitrogênio, com o avançar da idade. Concluindo que, com o avançar da idade, ocorre aumento nos coeficientes de digestibilidade da energia bruta e nos valores de energia metabolizável deste resíduo, o que significa que o resíduo do tomate pode melhor ser aproveitado a partir da fase inicial.

Lira et al. (2011) também realizou ensaio de metabolismo em duas idades de frangos de corte, de 1 a 7 dias e de 10 a 17 dias, objetivando avaliar o efeito da idade sobre os valores nutricionais do resíduo da goiaba e concluíram que não houve diferenças significativas para a energia metabolizável aparente, para a energia metabolizável aparente corrigida para nitrogênio e nem para o coeficiente de metabolizabilidade da energia bruta em função da idade.

Corroborando com Lira et al (2011), Carvalho et al. (2011) em trabalhos sobre o efeito da idade do frango sobre o valor energético do farelo de soja, observaram que os valores de energia metabolizável do farelo de soja, os balanços e os coeficientes de metabolizabilidade dos nutrientes da 
dieta-teste aumentaram com a idade do frango de corte.

Queiroz et al (2015) observaram, em ensaios sobre valor nutricional de milho e sorgo para frangos corte em idade inicial e de abate, que aves em idade de abate apresentam maiores valores de energia metabolizável aparente e energia metabolizável aparente corrigida para nitrogênio e de digestibilidade do nitrogênio e do extrato etéreo.

Em poedeiras semipesadas de 28; 65 e 110 dias, Sauceda (2017) realizou experimento de metabolizabilidade avaliando a inclusão de fitase nas dietas, avaliação do desempenho e da qualidade dos ovos. A qualidade externa dos ovos foi prejudicada com o avanço da idade das aves, em que as aves de 28 semanas produziram ovos mais leves que as aves com 65 e 110 semanas. No entanto, a qualidade da casca diminui com o avançar da idade e a qualidade interna do ovo não foi alterada com a idade das poedeiras, demonstrando que a metabolizabilidade foi diferente entre as idades e que as aves com 110 semanas apresentaram melhor eficiência.

Efeito do nível de inclusão e de substituição

Com relação ao efeito do nível de inclusão sobre os valores nutricionais dos alimentos, é sabido que as técnicas para avaliação de alimentos têm sofrido modificações ao longo do tempo, sem um estudo criterioso da qualidade dos dados gerados, com dúvidas a respeito do número de repetições, que varia de 4 a 7 entre os vários estudos sobre metabolismo, dos níveis de substituição, que variam de 20 a $40 \%$ dos ingredientes de origem vegetal e animal nas rações testes, podendo gerar, dependendo do nível de inclusão do ingrediente rações mais ou menos desbalanceadas nutricionalmente e dúvidas sobre o número ideal de dias para adaptação às rações-teste e para a coleta de excretas.

Segundo Sibbald (1975) o nível de consumo do alimento é um dos fatores que mais influenciam nos resultados de energia metabolizável, que podem variar com o nível de ingestão e com o nível de substituição do alimento-teste pela ração referência, pois, sob condições padronizadas, a excreção de energia fecal metabólica mais a urinária endógena é constante. Quando o nível de ingestão é alto a influência das perdas metabólicas é pequena; entretanto quando o consumo é baixo, essas perdas podem diminuir consideravelmente os valores de energia metabolizável.

Assim, visando se determinar o efeito da porcentagem de substituição do ingrediente teste na dieta referência sobre a 
energia metabolizável aparente, Paula et al. (2002) realizaram estudos sobre os valores de energia metabolizável da farinha de carne e ossos e farinha de vísceras determinados com diferentes níveis de substituição em frangos de corte pelo método tradicional de coleta total de excretas e observaram que, aumentando-se o nível de substituição na dieta referência diminui-se os valores de energia em todos os tipos de farinhas, porém o nível de $30 \%$ apresentaram melhores valores.

Nascimento et al. (2005) também realizou ensaio de metabolismo, pelo método de coleta total de excretas, objetivando avaliar o efeito dos níveis de substituição $(5,10,20,30$ e 40\%) da farinha de vísceras e da farinha de penas sobre os valores de energia metabolizável, observando que com o aumento do nível de substituição dos alimentos pela dieta referência ocorreu diminuição no valor energético dos mesmos.

Lira et al (2011) em ensaios de metabolismo objetivando avaliar o efeito com do nível de inclusão de $20 \%$ do resíduo da goiaba na dieta de frangos de corte, nas fases de 1 a 7 dias e de 10 a 17 dias, e observaram que os valores de energia metabolizável aparente, aparente corrigida e dos coeficientes de metabolizabilidade da energia bruta da ração teste, com a inclusão de $20 \%$ do resíduo da goiaba, diferiram dos valores da ração referência, nas duas idades, indicando que houve efeito negativo da inclusão de $20 \%$ do resíduo esses valores, o que foi atribuído ao conteúdo alto de fibra do resíduo, uma vez que vários autores relataram o efeito que a fibra exerce sobre a digestibilidade dos nutrientes das rações de frangos de corte. Kirchgessner et al. (1986) atribuíram a digestibilidade baixa de vários nutrientes dos alimentos a uma relação inversa com o seu conteúdo de fibra em detergente ácido, o que se observa nos valores de composição química do resíduo da goiaba apresentados nesta pesquisa.

Lira et al (2011) ainda realizou em ensaios de metabolismo objetivando avaliar o efeito do nível de inclusão de $30 \%$ do resíduo do tomate na dieta de frangos de corte, nas fases de 1 a 7 dias e de 10 a 17 dias, e observaram que a ração teste, com a inclusão de $30 \%$ do resíduo do tomate, diferiu da ração da ração referência nos valores de energia metabolizável aparente, aparente corrigida e no coeficiente de metabolizabilidade da energia bruta, nas duas idades, indicando que houve efeito negativo da inclusão de $30 \%$ do resíduo o valor nutricional da ração, também, atribuído ao percentual alto de fibra na composição do resíduo.

Frank et al. (2016) avaliou o efeito de níveis de inclusão sobre os valores energéticos de silagem de grão de milho 
para frangos de corte, em que a ração referência foi substituída em 10\%, 20\%, $30 \%$ ou $40 \%$ pela silagem e observaram que os valores energéticos da silagem de

\section{CONSIDERAÇÕES FINAIS}

Além do conhecimento da composição química do alimento, o conhecimento da digestibilidade dos nutrientes, da digestibilidade e disponibilidade dos aminoácidos, dos fatores que interferem na digestibilidade e a

\section{REFERÊNCIAS}

ABRAHÃO, J.J.S. Valor nutritivo de plantas forrageiras. In: CURSO DE ATUALIZAÇÃO EM PASTAGEM, 1991. Anais... Cascavel: Organização das Cooperativas do Estado do Paraná, 1991. p.209-225.

ALBINO, L.F.T. Sistemas de avaliação nutricional de alimentos e suas aplicações na formulação de rações para frangos de corte. Tese (Doutorado em Zootecnia) Universidade Federal de Lavras, Lavras, MG. 1991. 141p.

BATAL, A.B.; PARSONS, C.M. Effects of age on nutrient digestibility in chicks fed different diets. Poultry Science, v.81, p. 400-407, 2003.

BRUM, P.A.R. et al. Determinação dos valores de composição química e da energia metabolizável de ingredientes para aves. Revista Brasileira de Ciência Avícola, Campinas, v.1, n.3, p.187-192, 1999.

BRUMANO, G. et al. Composição química e valores de energia metabolizável de alimentos protéicos determinados com milho foram, negativamente, influenciados pelos níveis de inclusão da silagem de milho.

correta avaliação das verdadeiras contribuições energéticas dos alimentos são particularmente importantes nas formulações de rações para o ótimo desempenho animal e economicamente viáveis.

frangos de corte em diferentes idades. Revista Brasileira de Zootecnia, v.35, n.6, p.2297-2302, 2006.

CARVALHO, F.B. Efeito da temperatura ambiente e da idade do frango sobre o valor energético do farelo de soja. Arq. Bras. Med. Vet. Zootec., v.63, n.6, p.14371445, 2011.

COUSINS, B. Enzimas na nutrição de aves. In: SIMPÓSIO INTERNACIONAL ACAV - EMBRAPA SOBRE NUTRIÇÃO DE AVES, 1999, Concórdia. Anais...: Embrapa, 1999. p. 118-132.

FRANK, R., et al. Determinação dos valores energéticos e aminoacídicos da silagem de grãos úmidos de milho para frangos de corte. Arch. Zootec. v. 65, n. 249, p.103-106, 2016.

FREITAS, E.R. Avaliação nutricional de alguns alimentos processados para aves por diferentes metodologias e suas aplicações na formulação de rações para frangos de corte. 2003, 129p, Tese (Doutorado em Zootecnia) - Universidade Estadual Paulista/Faculdade de Ciências Agrárias e Veterinárias, Jaboticabal, SP. 
KATANGOLE, J.B.D.; MARCH, B.E. Fat utilization in relation to intestinal fatty acidbrinding protein and bile salts in chicks of different ages and different genetic sources. Poultry Science, v.59, p.819-827, 1980.

KIRCHGESSNER, M.; KURZINGER, H.; SCHWARZ, F.J. Digestibility of crude nutrientes in different feeds and estimation of their energy content of carp (cyprinus carpio). Aquaculture, v. 58, p. 185-194, 1986.

LIMA, L. I. SILVA, D.J.; ROSTAGNO, H.S. Composição química e valores energéticos de alguns ingredientes determinados em pintos e galos, utilizando duas metodologias. Revista Brasileira de Zootecnia, v.18, n.6, p.547-556, 1989.

LIRA, R. C. Valor nutricional e utilização do resíduo da goiaba (Psidium guajava L.) e do tomate (Lycopersicum esculentum Mill.) na alimentação de frangos de corte / Rosa Cavalcante Lira. 2008. 105p Tese (Doutorado em Zootecnia ) - Universidade Federal Rural de Pernambuco.

Departamento de Zootecnia. 2008.

MAIORKA, A. Estudo da regulação do consumo em frangos através de dietas com diferentes níveis energéticos na ração. In: REUNIÃO ANUAL DA SOCIEDADE BRASILEIRA DE ZOOTECNIA, 37. 2000, Viçosa, MG. Anais... Viçosa, MG: SBZ, 2000.

MACARI, M.; FURLAN, R.; GONZALES, E. Fisiologia aviária aplicada à frangos de corte. Jaboticabal: FUNEP, 1994. 296p.

MEDEIROS, S.L.S.; SANTIAGO, G.S.; VELOSO, J.A.F. Fibra - composição química e seu efeito na nutrição de suínos. Belo Horizonte: Escola Veterinária UFMG, 1988. p.15-22. (Caderno Técnico, 26).
MELLO, H.H.C. et al. Valores de energia metabolizável de alguns alimentos obtidos com aves de diferentes idades. Rev. Bras. Zootec., v.38, p.863-868, 2009.

MENTEN, J.F. M. Valores de energia metabolizável de milho e farelo de soja para frangos de corte na fase pré-inicial. In: REUNIÃO ANUAL DA SOCIEDADE BRASILEIRA DE ZOOTECNIA, 39. 2002, Recife. Anais... Recife, MG: SBZ, 2002.

MISIR, R.; SAUER, W.C. Effect of starch infusion at the ileum on nitrogen balance and apparent digestibilitis of nitrogen and amino acids in pig feed meat-and bone soybean meal diets. Journal of Animal Science, Champaign, v.55, n.3, p.599-607, 1982.

NASCIMENTO, A.H. et al. Valores de energia metabolizável de farinhas de penas e de vísceras determinadas com diferentes níveis de inclusão e duas idades das aves. Revista Brasileira de Zootecnia, v.34, n.3, p.877-881, 2005.

NATIONAL RESEARCH COUNCIL. Board on Agriculture. Committee on Animal Nutrition. Subcommittee on Poultry Nutrition. Washington D.C: National Academy Press, 1994. 155p.

NITSAN, Z.; DUNNING, E.A.; SIEGEL, P.B. Organ growth and digestive enzyme levels to fifteen days of age in lines of chickens differing in body weight. Poultry Science, v.70, p.2040-2048, 1991.

NOBLET, J.; LE GOFF, G. Effect of dietary fiber on the energy value of feeds for pigs. Animal Feed Science and Technology, Madri, v. 90, p. 35-52, 2001.

PANIGRAHI, S. Effect of different copra meals and amino acid supplementation on broiler chick growth. British Poultry Science, v.33, p.683-687, 1992. 
PARSONS, C.M.A. POTTER, L.M.; BLISS, B.A. True metabolizable energy corrected to nitrogen equilibrium. Poltry Science, Champaign, v.61, n.11, p. 2241 2246, 1985.

PAULA, A.; et al. Valores de energia metabolizável de farinha de carne e ossos e farinha de vísceras determinados com diferentes níveis de substituição para frangos de corte. Revista Brasileira de Agrociência, Pelotas, v.8, p.51-55, 2002.

QUEIROZ, A. P. L. B. de. et al. Composição bromatológica, energia metabolizável e digestibilidade de nitrogênio e extrato etéreo de amostras de milho e sorgo para frangos de corte em diferentes idades. Vet. Not.,v.21, n. 1, p.30-40, jan./jun. 2015.

ROSTAGNO H.S. et al. Composição de alimentos e exigências nutricionais Tabelas brasileiras para aves e suínos. Viçosa: UFV, 2000. 141p.

ROSTAGNO H.S. et al. Composição de alimentos e exigências nutricionais Tabelas brasileiras para aves e suínos. Viçosa: UFV, 2005.141p.

SAKOMURA, N.K.; et al. Efeito da idade dos frangos de corte na atividade enzimática e digestibilidade dos nutrientes do farelo de soja e da soja integral. Revista Sociedade Brasileira de Zootecnia, v.33, n.4, p.924-935, 2004.

SIBBALD, I.R. The effect of level of feed intake on metabolizable energy values measured with adult roosters. Poultry Science, Champaingn, v.54, n.6, p.19901997, Nov. 1975.

SOARES, K.R.et al. Valores de energia metabolizável de alimentos para pintos de corte na fase pré-inicial. Ciênc. Agrotec., v.29, p.238-244, 2005.
TORRES, D.M. Valor nutricional de farelos de arroz suplementados com fitase, determinado por diferentes metodologias com aves. 2003. 172p. Tese (Doutorado em Zootecnia) - Universidade Federal de Lavras, Lavras, MG.

WENK, C.The role of dietary fibre in the digestive physiology of the pig. Animal Feed Science and Technology, Madri, v. 90, p.21-33, 2001.

WHITEHEAD, G.C.; FISCHER, C. The utilization of various fats by turkey of different ages. British Poultry Science, v.38, n.1, p.28-35, 1982. 